\title{
The Productivity Gap Among Major European Countries, USA and Japan
}

\author{
Giorgio Calcagnini $^{1}$ (D) Germana Giombini ${ }^{1,2}{ }_{(\mathbb{D})} \cdot$ Giuseppe Travaglini $^{1}$ (iD
}

Received: 14 January 2020 / Accepted: 18 September 2020 / Published online: 7 October 2020

(c) The Author(s) 2020

\begin{abstract}
This paper analyzes Total Factor Productivity (TFP) in five European countries (France, Germany, Italy, Spain, and UK), the USA and Japan between 1954 and 2017. It uses the common trend- common cycle (CTCC) approach to decompose series in trends and cycles. We find that the seven economies are structurally different and differently affected by similar shocks. We show that trend and cycle innovations are, in most of the cases, negatively correlated as predicted by the 'opportunity cost' approach to productivity growth, and that trend innovations are larger than cycle innovations. We provide an interpretation for countries' differences in TFP performance in recent years that is related to the so-called 'deep' determinants in growth literature, such as the presence of efficient markets and institutions. Finally, we present a comparison with the traditional Hodrick and Prescott deterministic filter to highlight the advantages of CTCC methodology that does not require a priori on the nature of the time series.
\end{abstract}

Keywords Total factor productivity $\cdot$ Cointegration analysis $\cdot$ Market imperfections

JEL Classification D24 · D43 · E02 · E23

\section{Introduction}

Productivity (as measured by output per unit of single input or total inputs), and its growth, is well recognized by essentially all economists as the key variable to long-run improvement in income and (un)employment. Most of the same economists would also agree that productivity depends upon a combination of investment in physical and human capital, knowledge and technical progress. However, the link between

\footnotetext{
$凶$ Germana Giombini germana.giombini@uniurb.it

1 Department of Economics, Society and Politics, Università di Urbino Carlo Bo, Urbino, Italy

2 DESP, Via Saffi 42, 61029 Urbino, Italy
} 
this combination and productivity may be considerably weakened by factors as the quality of institutional and market efficiency, the degree of openness and flexibility of the economy (Saltari and Travaglini 2010; Calcagnini et al. 2015, 2018; Fuentes et al. 2014). Moreover, the dynamics of innovation and economic performance may be shaped by interconnections and complex relationships between the ability of industries to turn out R\&D efforts into successful innovations, which in turn lead to high entrepreneurial profits, and the commitment of industries to invest profits in further technological efforts (Bogliacino and Pianta 2013). Therefore, understanding the factors behind productivity is a complex process because more than a single determinant can be significant at the same time (World Economic Forum 2014, p. 4).

This paper aims at analyzing Total Factor Productivity (TFP) in five major European countries (France, Germany, Italy, Spain and UK), USA, and Japan between 1954 and 2017. We employ annual data and focus on countries that have similar degrees of economic development. The latter choice should provide us with some advantages, with respect to a more heterogeneous sample of countries, when studying the stochastic properties of their productivity. Indeed, we expect that the probability that these seven countries share a larger number of stochastic trends and cycles is higher than in the case of a larger 'club' of countries with different levels of economic development. The choice to analyze only the seven countries mentioned above is, therefore, pivotal to our analysis. Indeed, these countries account for $45 \%$ and $71 \%$ of the 2018 world's and high-income countries' GDP, respectively. ${ }^{1}$ Increasing the number of countries would likely make the identification of the TFP's short- and long-run components more difficult, with only a marginal improvement in our understanding of the productivity dynamics in advanced and internationally integrated economies. Further, we aim at separating the secular-nonstationary (trend) component from the cyclical-stationary one without imposing any a priori restriction on their relationship, and at focusing on the so-called 'deep' determinants of TFP, which may still be different from one economy to another, even within the European market.

To calculate the secular-nonstationary component of the TFP, we employ the multivariate procedure developed by Vahid and Engle (1993), Engle and Issler (1995) and Kozicki (1993), known as the common trends-common cycles (CTCC) approach. This methodology has the appealing feature that, in the special case where the number of common trends $(c t)$ and common cycles $(c c)$ adds up to the number of time series $(t s)$, trend and cyclical components can be calculated as simple linear combinations of the data. Further, in this special case we are able to identify trend and cycle components without imposing a priori conditions on the relationships existing among the different type of shocks in the economy, as in the case of other time series decomposition analyses (i.e. Blanchard and Quah 1989).

Common trends are identified in the context of cointegrating relationships. Evidence of a single common trend would suggest that productivity time series reflect common structural characteristics across economies and that the levels of Total Factor Productivity converge in the long run. Common cycles, on the other hand, are short-run relationships linking stationary series. If the seven economic cycles depend upon the same shocks, a single common cycle can be identified as evidence of business cycle

\footnotetext{
1 Our calculations on The World Bank data http://wdi.worldbank.org/table/4.2.
} 
synchronization (Aguiar-Conraria and Soares 2011; Calcagnini 1995; Calcagnini and Travaglini 2014; Degiannakis et al. 2014).

The novelty of our work is that the CTCC methodology allows to understand how short- and long-run common shocks determine changes in measured TFP for the major OECD countries. Indeed, we show that the long-run dynamics of TFP, notwithstanding countries have access to and share the same technology and knowledge capital, is not the result of a common trend because of the structural differences ('deep' determinants) that characterize each economy. On the contrary, our analysis shows that the seven countries are short-run synchronized, i.e. they share one common TFP cycle. The latter is likely the result of national monetary and fiscal policies increasingly coordinated among the most developed economies (Calcagnini 1995; Inklaar et al. 2008; Furceri and Karras 2008).

Empirical work that uses long-run time series is subjected to a major drawback, i.e. the likely presence of large discontinuity (breaks). Researchers' effort to understand whether the observed episodes are the result of segmented deterministic trends and level shifts or of stochastic forces affecting the secular component has not reached a solid conclusion yet (Nelson and Plosser 1982). In other words, are growth paths better described by a trend-stationary model with relatively few structural breaks (either in growth or in levels) or by unit root processes in which permanent stochastic shocks are responsible for continuous changes?

Our approach is more in line with the latter interpretation and with two strands of the economic literature. The first one refers to endogenous growth models, according to which exogenous shocks affect the accumulation of physical and human capital or $\mathrm{R} \& \mathrm{D}$ expenditures that cause shifts in the equilibrium growth rate of the economy (Lucas 1988; Romer 1986). The second approach refers to evolutionary models that emphasize out-of-equilibrium dynamics and can hardly be reconciled with a trendstationary data generating process (Dosi et al. 2019). Moreover, this class of models allows for demand-driven fluctuations that may affect the long run path of the economy via their interaction with firms' innovation patterns (Lamperti et al. 2018) and, therefore, growth is inherently stochastic as it results from the aggregation of endogenous stochastic innovations at the microeconomic level and, therefore, models are probably better approximated by path-dependent processes akin to random walks. ${ }^{2}$

We obtain several results.

First, measured TFP shows different dynamics across the seven economies. Germany and France recorded the strongest mean growth rates along the whole period. However, France showed negative growth rates in the most recent period (2008-2017). Differently from France, Germany, Japan, UK and the USA recorded positive mean TFP growth rates during the whole period. Finally, Italy shows the strongest decrease in TFP during the period 2008-2017.

Second, we show the existence of only one cointegrating relationship among the Total Factor Productivity time series of the seven countries. This result implies that the seven time series share six stochastic trends that means no convergence of national

\footnotetext{
2 See Russo et al. (2019), p. 2.
} 
TFP levels. ${ }^{3}$ In other words, the same shock produces different results in each country because of the different economic and institutional environment in which they occur.

Third, we find that the seven time series share a single TFP cycle. The latter result implies that business-cycle shocks determine a profile of the short-run TFP similar in all countries, likely as a consequence of their strong economic integration and coordination of their economic policies. Having found only one common TFP cycle, the sum of stochastic trends (six) and common cycles (one) add up to the number of the time series (seven), which technically implies that there is only one way, in each country, to separate Total Factor Productivity into trends from cycles.

Fourth, trend and cycle shocks are correlated. Indeed, the correlation coefficient between the two types of shock is negative and statistically significant in six out of the seven countries, the only exception being the USA.

Fifth, we find that trend innovations are generally larger than cycle innovations. Trend innovations are relatively smaller in Spain and the USA than in the other countries. This empirical feature is naturally addressed within neoclassical models with long-run changes in technologies and government policies (Hansen and Ohanian 2016). This finding shows that lower frequency component of fluctuations are quantitative important, and deserve attention. In this paper we contribute to the advancing the understanding of secular movements in productivity, suggesting that actual economic policies have affected resource allocation and productivity loss.

Overall, these results mean that in the long run a $1 \%$ shock to productivity trend determines a $1 \%$ increase in the level of Total Factor Productivity. Moreover, the negative relationship observed between trend and cycle innovations supports the 'opportunity cost' approach to productivity growth (Saint-Paul 1993). According to it, the intertemporal substitution of productivity-improving activities along the business cycle predicts that recessions are associated with a higher pace of productivityimproving activities. Thus, for a given negative shock, these economies seem to react by reallocating resources and obtaining the largest improvement on long-run Total Factor Productivity, even though the size of the improvement differs across the seven countries.

Data on the most recent sub-period, for which we were able to collect information, seem to support our hypothesis according to which long-run TFP performance is related to the so-called 'deep' determinants of economic growth. ${ }^{4}$ Some authors have recently suggested the hypothesis of secular stagnation, according to which productivity growth has slowed because of a decline in innovation or, possibly, inadequate private and public spending (Summers 2014). According to other scholars, TFP slumps seem to be determined by country specific factors, such as educational attainment, weak political systems, and global factors, such as higher risk, and higher energy prices (Eichengreen et al. 2017). Our conclusion on the relationship between the long-run TFP performance and the 'deep' determinants of economic growth is not the result of a 'formal' analysis, i.e. by means of an empirical model that links the long-run TFP performance of each country to the functioning of their markets and institutions. This can hardly be done because the 'deep' determinants of economic growth do not exhibit

\footnotetext{
${ }^{3}$ See Sondermann (2012), Bernard and Durlauf (1995).

${ }^{4}$ On this topic see Isaksson (2007).
} 
enough variability, even in the long run, to effectively explain TFP variability. Further, measures of the efficient functioning of markets and institutions are available for a time span considerably shorter than that of TFP, and the consensus on how effectively these variables do their work is not as broad as you would expect. Therefore, we made a tentative experiment and chose to focus on a few indicators relating to the ease of doing business and competitiveness in each country. Then we checked if and how the previous indicators are correlated to a measure of each country's innovation, i.e, the number of positive shocks of the TFP secular trend. We find that the characteristics of trend innovations are positively related with the quality of institutions that enhance business activity. ${ }^{5}$ Our results, though essentially descriptive and not generalizable given the limited number of observations, are consistent with our hypothesis that in those economies equipped with greater growth potential (i.e., the presence of efficient markets and institutions) trend positive shocks turn into stronger GDP growth.

Finally, in the last section of the paper we compare our CTCC decomposition with that based on the Hodrick and Prescott $(1981,1997)$ (HP) filter.

However, it is important to emphasize that this comparison should not be considered as a 'robustness test' of our CTCC results since any ad-hoc decompositions of the stochastic or deterministic properties of time series can generate different outcomes. In addition, deterministic filters, such as HP, cannot address the topic at the core of our analysis, i.e. how much the common stochastic components, if any, determine the dynamics of trends and cycles. Notwithstanding, the comparison provides additional useful information on the nature of the time series and their components.

The paper is organized as follows. The next section provides a brief description of the theoretical framework of the CTCC approach. Section 3 describes the data, and results from the common trend-common cycle approach. Section 4 discusses our main findings and their implications for economic policies, while Sect. 5 shows findings from the HP decomposition. The final Section concludes.

\section{Common Trends and Common Cycles: Theoretical Framework}

The CTCC method is based on the joint analysis of the degree of short- and long-run comovements in the Total Factor Productivity series of the seven economies. This methodology works under the assumption that the data contain unit-roots, therefore stochastic trends. Searching for common trends amounts to performing cointegration tests, which can be interpreted as long-run comovement tests. Cycles are modeled as transitory but persistent processes, which may be common to several economies. Such cycles reveal all synchronized persistence in TFP series, describing their short-run comovement. Testing for common cycles amounts to searching for independent linear combinations of the (level of the) TFP series that are random walks, thus cycle free. The test therefore is a search for linear combinations of the first differences of the variables whose correlation with the elements of the past information is zero. Past

\footnotetext{
5 Gehringer et al. (2016) find that rationalization, human capital and information and communication technologies are the main drivers of predicted TFP in the European Union.
} 
information is formed by the lagged first differences of TFP series and a number of error correction (EC) terms equal to the cointegration rank (Vahid and Engle 1993). ${ }^{6}$

Common trends and common cycles appear in the macroeconomics literature in several theoretical models. ${ }^{7}$ One reason is that '...the estimates of trends and cycles of the data allow to answer a question considered important by most authors in the applied macroeconomics literature: do permanent or transitory shocks explain the bulk of the variance of aggregate data?' (Issler and Vahid 2001, p.460).

Moreover, the use of cointegrating restrictions (if correctly imposed) leads to efficiency gain in estimating the dynamic models of many economic time series. It is expected that efficiency gain can be enhanced by using common-factor restrictions on short-run components (common cycles). The joint use of common-trend and commoncycle restrictions would lead to more precise estimates of the dynamic models than those based on common-trend restrictions alone or on alternative methods.

Finally, in the special case where the number of common trends (ct) and common cycles (cc) adds up to the number of time series (ts), trend and cyclical components can be calculated as simple linear combinations of the data, without imposing a priori conditions on the relationships existing among the different type of shocks in the economy. Even if the convenience of recovering trends and cycles as linear combinations of data is lost when the above condition does not hold, imposing reduced-rank restrictions on the VECM continues to increase the efficiency of the results.

\section{Data and Empirical Analysis}

\subsection{TFP: The Penn World Table 9.1}

Our analysis makes use of Total Factor Productivity time series (at constant national prices) from the University of Groningen and the University of California, Davis for the period 1954-2017 that are included in the Penn World Table (PWT) 9.1. ${ }^{8}$ Making use of prices collected across countries in benchmark years by the International Comparisons Program (ICP), and using these prices to construct purchasing-power-parity (PPP) exchange rates, PWT converts gross domestic product (GDP) at national prices to a common currency, U.S. dollars, making them comparable across countries (Feenstra et al. 2015, p. 3150).

There are a number of measurement issues related to TFP that need to be considered. Among them, the need to correctly estimate capital and labor inputs. Further, the basic Solow residual calculation assumes that the factors of production are flexible and fully employed (Solow 1957). This may not be the case if there are costs involved in hiring and firing or in installing new machines and equipment. Finally, firms may respond to short-run fluctuations in demand by varying the degree of capital (and labor)

\footnotetext{
6 The EC is the one calculated on the basis of the cointegration vector.

7 The existence of both common trends and common cycles can be illustrated by the standard real business cycle model of King et al. (1988). As discussed in Issler and Vahid (2001), the dynamic stochastic general equilibrium model developed by King et al. (1988) suggests that output, consumption and investment have a common trend and a common cycle.

8 Time series are available at https://www.rug.nl/ggdc/productivity/pwt/.
} 
utilization. ${ }^{9}$ Some of these measuring issues have been taken care in calculating TFP time series included in the most recent version available of the Penn World Table (PWT) 9.1.

First, Version 9.1 PWT includes measures of physical and human capital and estimates of productivity based on the translog production function, which allows for substitution elasticities to differ across countries and over time (Feenstra et al. 2015).

Second, the share of labor income in GDP is estimated and combined with measures of human capital to arrive at measures of total factor productivity (TFP). The index of human capital per worker is based on the average years of schooling, and an assumed rate of return for primary, secondary and tertiary education.

Third, differently from the previous version PWT 9.0, the productive capital input is based on capital services instead of the capital stock. The measure of physical capital is obtained by the estimation of the user cost of capital and comparing the implicit rental price of capital and the level of capital services rather than capital stock. The user cost of capital is based on asset-specific rate of depreciation. Thus, the depreciation rate varies across countries and over time. By moving to a capital services framework, each capital input is treated symmetrically with labor input as a relative input level, weighted by the revenue share of that factor input. As a result, the relative TFP levels tend to be higher relative to the United States based on the PWT 9.1 methodology than based on the previous methodology, but with no systematic pattern across countries (Inklaar et al. 2019).

Finally, PWT 9.1 includes a TFP measure that allows for comparisons across countries at a point in time (variable CTFP) and a measure that allows comparisons within countries across the years $\left(\operatorname{RTFP}^{N A}\right)$. In this paper we make use of $\operatorname{RTFP}^{N A}$ because of the time-series nature of our analysis. All RTFP ${ }^{N A}$ time series are annual indexes with base 2011 = 100 and span from 1954 to 2017 (Feenstra et al. 2013, 2015).

There are some caveats concerning the use of Total Factor Productivity time series. Lipsey and Carlaw (2000) provide nine different quotations referred to TFP measures taken from the economic literature and group them in three main positions:

- Changes in TFP measure the rate of technical change;

- TFP measures only the free lunches of technical change, which are mainly associated with externalities and scale effects;

- TFP measures anything useful. ${ }^{10}$

Our approach to the use and meanings of TFP is somewhat eclectic. We still interpret changes in TFP as a measure of modifications occurred in the way the economy generates income, suggesting that these changes are related to types of externalities, such as institutions or market imperfections.

Keeping in mind these caveats, we now move to data analysis.

The dynamics of the seven TFP series are plotted in Fig. 1, while Fig. 2 shows the corresponding TFP rate of growth. Shaded areas represent two of most important time periods in terms of economic growth for developed economies, which are common to all seven countries. The first shaded area refers to the fabulous Sixties during which

\footnotetext{
9 See Groth et al. (2004).

10 According to Griliches (1994), TFP is at best a measure of our ignorance.
} 


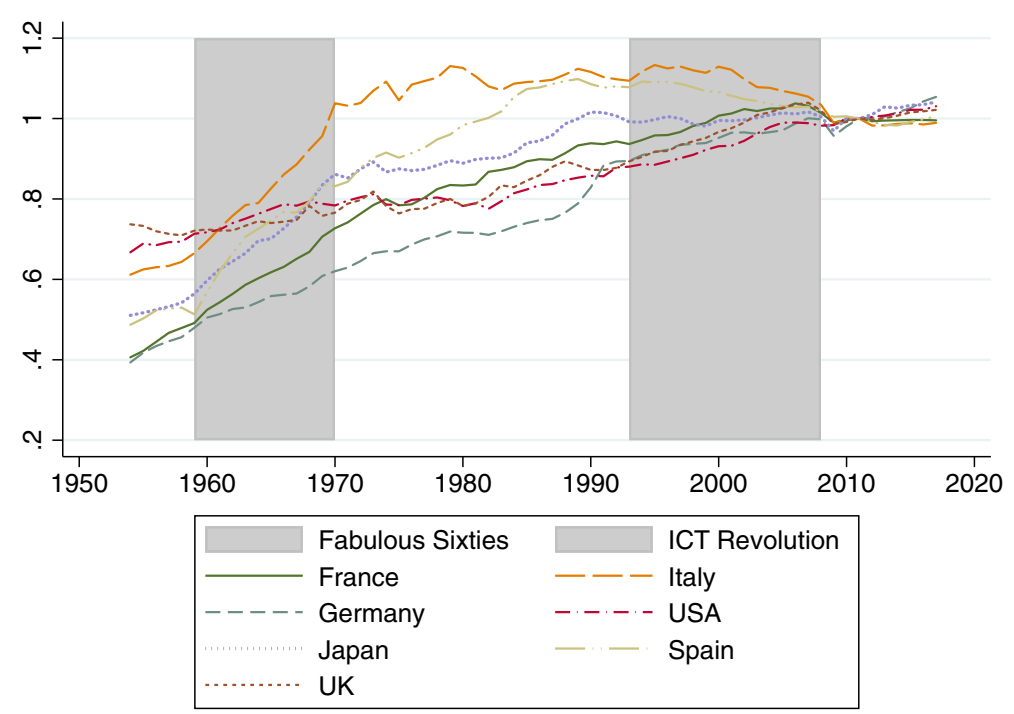

Fig. 1 Total factor productivity dynamics
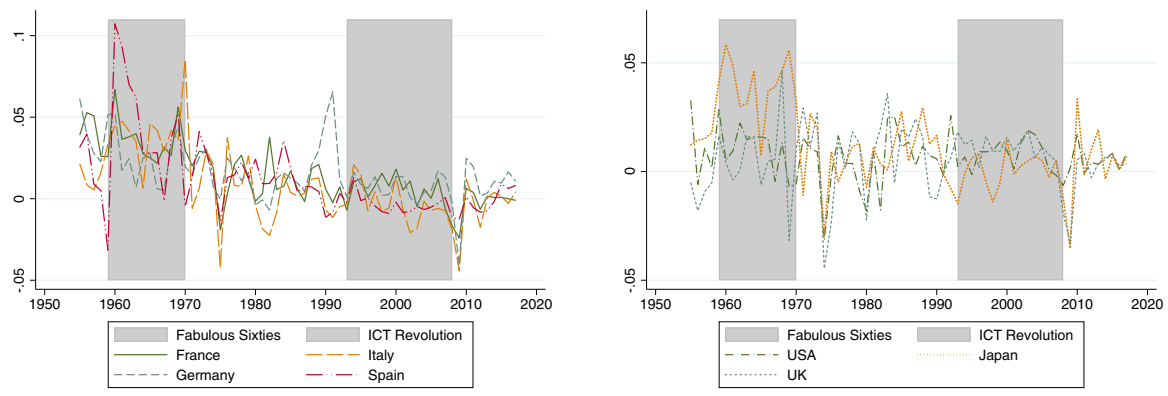

Fig. 2 Total factor productivity growth

the TFP recorded an increase as a consequence of a prolonged expansion in investment in the years following the end of the second world war. The second one, which again mark another phase of increasing TFP, refers to the time period that starts in the early Nineties characterized by the diffusion of ICTs and Internet as main driving forces of economic growth. Particularly, Internet drove business transformation and economic modernization by also rejuvenating traditional activities. Indeed, the Internet technology has enabled fundamental business transformations that spans the entire value chain in virtually all sectors and types of companies (see Dedrick et al. 2003; Manyika and Roxburgh 2011; Antonelli et al. 2013). The economic crisis of 2008 seems to have only temporarily stopped the increasing trend of TFP that, instead, continued to growth only in Japan, Germany, the UK and the USA. In the most recent years the TFP growth rates are negative in Spain, France, and Italy. Therefore, the former club of countries returned to their pre-crisis TFP levels faster than the latter. 
Table 1 Total factor productivity growth rates (means of annual percentage growth rates). . Source: Our calculations on data from University of Groningen and University of California, Davis. PWT 9.1-total factor productivity at constant national prices

\begin{tabular}{llc}
\hline & $1954-2017$ & $2008-2017$ \\
\hline Germany & 1.59 & 0.62 \\
France & 1.45 & -0.20 \\
Italy & 0.79 & -0.48 \\
Japan & 1.15 & 0.42 \\
Spain & 1.18 & -0.12 \\
UK & 0.53 & 0.02 \\
USA & 0.71 & 0.54 \\
\hline
\end{tabular}

Figure 2 shows that the means of annual percentage growth rates of TFP over the whole period show significant differences among the seven economies. Indeed, Germany and France record the largest average growth rate at $1.59 \%$ and $1.45 \%$ per year respectively, followed by Spain and Japan (1.18\% and $1.15 \%$, respectively) (see Table 1). Column 2 of Table 1 shows mean TFP growth rates for the most recent period (2008-2017). It is worthwhile noting that Italy records the largest negative TFP growth rate $(-0.48 \%)$, followed by France $(-0.20 \%)$ and Spain $(-0.12 \%){ }^{11}$

\subsection{Common Trends and Common Cycles in TFP}

To obtain a more precise description of TFP we rely on the common trend-common cycle (CTCC) method developed by Vahid and Engle (1993), Engle and Issler (1995), and Kozicki (1993).

The CTCC methods requires three fundamental steps.

The first step is a test of Total Factor Productivity nonstationarity. This was carried out by means of the Modified Dickey-Fueller (DF-GLS) test. ${ }^{12}$ Results from the DFGLS test are shown in Table 2 and support the null hypothesis of nonstationarity for all seven time series. ${ }^{13}$

The second step involves tests for the presence of cointegration among the series. We employ Johansen's $(1988,1991)$ technique, which estimates the number of linearly independent cointegrating vectors $(r)$. We consider the data as being approximately well described by a Vector Autoregression model (VAR) with a restricted (linear) time trend both in the cointegration space and data ('Model 1' in the context of the Johansen's methodology). ${ }^{14}$ Table 3 shows Johansen's trace statistic test for the system containing the time series of Total Factor Productivity for Germany, France, Italy

\footnotetext{
11 A less dynamic business growth distribution is associated with lower productivity growth. Importantly, both a higher share of growing and shrinking firms are correlated with faster productivity growth. Indeed, European countries have on average a lower share of high-growth firms than the US. But they also have fewer medium-growth firms and fewer shrinking firms. At the same time, Europe has a much larger share of 'static' firms, that is, firms that neither expand nor contract in a 3-year period (Bravo Biosca 2010).

12 Elliott et al. (1996), and later studies, have shown that this test has significantly greater power than the previous versions of the augmented Dickey-Fuller test.

13 Unit root tests confirm that the first differences of the original series are $\mathrm{I}(0)$.

14 See previous footnote.
} 
Table 2 Augmented Dickey-Fuller (DF-GLS) test: 1956-2017

\begin{tabular}{llll}
\hline & Test statistic & $5 \%$ critical value & Optimal lag \\
\hline Germany & -1.670 & -3.150 & 1 \\
France & -0.728 & -3.032 & 4 \\
Italy & -1.470 & -2.935 & 6 \\
Japan & -1.068 & -3.076 & 3 \\
Spain & -2.068 & -2.831 & 8 \\
UK & -2.009 & -2.985 & 5 \\
USA & -2.135 & -2.985 & 5 \\
\hline
\end{tabular}

Null: time series is nonstationary

Table 3 Johansen tests for cointegration: 1955-2017 ( $\mathrm{r}=$ number of cointegrating relationships)

\begin{tabular}{lllll}
\hline Null & Log likelihood & Eigenvalue & Trace statistic & 5\% critical value \\
\hline $\mathrm{r}=0$ & 1337.8 &. & 171.0 & 146.76 \\
$\mathrm{r}<=1$ & 1367.1 & 0.61 & $112.37^{*}$ & 114.90 \\
$\mathrm{r}<=2$ & 1385.6 & 0.44 & 75.36 & 87.31 \\
$\mathrm{r}<=3$ & 1399.1 & 0.35 & 48.37 & 62.99 \\
$\mathrm{r}<=4$ & 1409.4 & 0.27 & 27.80 & 42.44 \\
$\mathrm{r}<=5$ & 1416.1 & 0.19 & 14.12 & 25.32 \\
$\mathrm{r}<=6$ & 1421.2 & 0.15 & 4.10 & 12.25 \\
$\mathrm{r}<=7$ & 1423.3 & 0.06 &. &. \\
\hline
\end{tabular}

Japan, Spain, UK and the USA. The first 'trace statistics' value smaller than the 5\% critical value is for $r<=1$. This result, combined with the rejection of the null that $r=0$, allows us to conclude that there is only one cointegration vector that, in turn, implies that TFP of the seven countries does not converge. The latter result is consistent with national economies characterized by different structures, institutions, market imperfections and, likely, by different technology shocks. ${ }^{15}$ Indeed, finding only one cointegrating vector rules out the possibility that TFP data of the seven countries have one common stochastic trend. Since the rank of the cointegrating space is 1 , the seven TFP series will share six idiosyncratic common trends.

Table 4 shows the estimated cointegration vector on the base of a Vector Error Correction Model (VECM) and conditioning on two lags of the endogenous variables. Estimated coefficients are statistically significant and all residuals passed autocorrelation tests, a desirable feature since Johansen's test assumes independent Gaussian errors. ${ }^{16}$

The third step involves tests for the existence of common cycles. The procedure developed by Vahid and Engle (1993) suggests looking for linear combinations of the series, i.e. Total Factor Productivity, that are uncorrelated with any linear combination of the RHS variables of the Error Correction Model formed with a number of error

\footnotetext{
15 On this topic see Bernard and Durlauf (1995).

${ }^{16}$ All residuals passed the normality tests, but Germany and France.
} 
Table 4 Cointegration vector estimates

\begin{tabular}{llll}
\hline & Coefficient & $\begin{array}{l}\text { Residual } \\
\text { Normality test } \\
\left(\text { Jarque-Bera, } \chi^{2}\right)\end{array}$ & $\begin{array}{l}\text { Residual } \\
\text { Autocorrelation test } \\
\left.\text { (Lagrange multiplier, } \chi^{2}\right)\end{array}$ \\
\hline USA & 1 & 0.992 &.. \\
Germany & $-1.706^{* * *}$ & 10.851 &.. \\
Italy & $(0.643)$ & &.. \\
France & $-1.895^{* * *}$ & 1.121 & \\
Japan & $(0.451)$ & &.. \\
Spain & $4.176^{* * *}$ & 6.870 &.. \\
UK & $(0.917)$ & &.. \\
All countries & $-1.921^{* *}$ & 2.269 &.. \\
Lag 1 & $(0.819)$ & & \\
Lag 2 & $1.225^{* *}$ & 1.935 &.. \\
\hline
\end{tabular}

***,**,* Statistically significant at the $1 \%, 5 \%$ and $10 \%$ probability level

correction terms equal to the cointegration rank. This is equivalent to imposing a reduced rank condition on the coefficient matrix of lagged TFP growth rates and error correction terms. Vahid and Engle suggest performing this reduced rank condition test by canonical correlation analysis. In this case, the cofeature rank, $s$, is the number of statistically zero canonical correlations and the number of common cycles is equal to the number of series minus $s$.

Table 5 shows the results of the common-cycle tests carried out by means of the Wilks' Lambda Statistic and its corresponding F-test of the null hypotheses that the current and all smaller canonical correlations are statistically zero. As noted before, the cofeature rank $s$ is the number of statistically zero canonical correlations. At the $5 \%$ level, the test cannot reject the hypothesis that the six smallest canonical correlations are statistically zero, which implies that $s$ is six. Thus, the seven TFP series share one common cycle and do have similar short-run fluctuations. This feature of the data set exemplifies the basic thrust behind Burns and Mitchell's (1946) research.

\section{Interpreting Common Trends and Cycles}

Once we have trends and cycles of each TFP series, we are able to calculate their innovations. In the case of stochastic trends, innovations are the first differences of the trend series, while in the case of cycles they are the residuals from regressing cycles on 
Table 5 Canonical correlation analysis: 1957-2017 (Wilk's Lambda test: significance of canonical correlation, $s$ )

\begin{tabular}{|c|c|c|c|c|}
\hline Null & $\begin{array}{l}\text { Canonical } \\
\text { correlations }\end{array}$ & $\begin{array}{l}\text { Wilk's } \\
\text { Lambda } \\
\text { statistic }\end{array}$ & $\begin{array}{l}\text { Degrees of } \\
\text { freedom } \\
\text { Num./Denom. }\end{array}$ & $\mathrm{F}$ \\
\hline$s=7$ & 0.889 & 0.076 & $56 / 253$ & $2.780 * * *$ \\
\hline$s=6$ & 0.587 & 0.360 & $42 / 223$ & 1.297 \\
\hline$s=5$ & 0.487 & 0.549 & $30 / 194$ & 1.045 \\
\hline $\mathrm{s}=4$ & 0.423 & 0.720 & $20 / 163$ & 0.852 \\
\hline $\mathrm{s}=3$ & 0.247 & 0.876 & $12 / 132$ & 0.565 \\
\hline $\mathrm{s}=2$ & 0.226 & 0.933 & $6 / 102$ & 0.598 \\
\hline $\mathrm{s}=1$ & 0.128 & 0.983 & $2 / 52$ & 0.435 \\
\hline
\end{tabular}

$* * *, * *, *$ Statistically significant at the $1 \%, 5 \%$ and $10 \%$ probability level

Table 6 Correlations between innovations and variance decomposition analysis (1955-2017)

\begin{tabular}{llcc}
\hline & Correlation coefficients & Trend innovations & \\
\hline Germany & $-0.93^{* * *}$ & 62.1 & Cycle innovations $^{\mathrm{b}}$ \\
France & $-0.97^{* * *}$ & 3.1 & 37.9 \\
Italy & $-0.97^{* * *}$ & 63.6 & 96.9 \\
Japan & $-0.93^{* * *}$ & 58.0 & 36.4 \\
Spain & $-0.95^{* * *}$ & 3.7 & 42.0 \\
UK & $-0.31^{* *}$ & 98.5 & 96.3 \\
USA & 0.11 & 97.4 & 1.5 \\
\hline
\end{tabular}

$* * *, * *, *$ Statistically significant at the $1 \%, 5 \%$ and $10 \%$ probability level

a $\%$ of the variance of TFP innovation attributed to trend innovations

$\mathrm{b} \%$ of the variance of TFP innovation attributed to cycle innovations

past information (cycles lagged 1 and 2). Decomposing each TFP series into trend and cyclical components raises the question of whether the cyclical innovations explain a significant proportion of the forecast errors of TFP fluctuations. To determine this, the relative importance of permanent and transitory shocks in explaining the variance of TFP is assessed using a forecast error variance decomposition (Issler and Vahid 2001; Chen and Mills 2009). ${ }^{17}$

Table 6 shows results of the correlation analysis between trend and cycle innovations in each country, and their variance decomposition analysis.

Trend and cycle innovations are negatively, and statistically significant, correlated in all countries, but the USA, supporting the 'opportunity cost' approach to productivity growth for these countries (Saint-Paul 1993). According to it, the intertemporal substitution of productivity-improving activities along the business cycle predicts that recessions are associated with a higher pace of productivity-improving activities. Thus,

\footnotetext{
17 In both cases we run Lagrange Multiplier tests to check for residual serial correlation. In all tests we accepted the Null of no residual serial correlation.
} 
Table 7 Number of positive trend innovations

\begin{tabular}{lllllll}
\hline & $\leq 1980$ & $1981-1990$ & $1991-2000$ & $2001-2010$ & $2011-2017$ & $1951-2017$ \\
\hline Germany & 15 & 7 & 7 & 6 & 7 & 42 \\
France & 13 & 6 & 5 & 4 & 7 & 35 \\
Italy & 13 & 4 & 6 & 2 & 6 & 31 \\
Japan & 15 & 7 & 5 & 4 & 7 & 38 \\
Spain & 14 & 6 & 5 & 3 & 7 & 35 \\
UK & 14 & 7 & 10 & 8 & 6 & 45 \\
USA & 18 & 9 & 8 & 8 & 5 & 48 \\
\hline
\end{tabular}

Innovations are the first differences of the stochastic trend series

countries during recessions react to negative shocks by restructuring their production system.

Illustrative of the differences that characterize the seven economies are the results of the variance decomposition of Table 6. Trend innovations are larger than cycle innovations in all countries, but France and Spain. This empirical feature may be addressed within macroeconomic models with long-run changes in technologies and government policies (Hansen and Ohanian 2016). The authors show the empirical importance of very long-run movements in aggregate variables relative to traditional business cycle fluctuations using long-run annual US data, and postwar European data. Further, they find that low frequency movements in aggregate time series are quantitatively large than the traditional business cycle component.

Finally, as the trend-innovation effects are permanent while the cycle-innovation effects are only transitory, and the trend innovation explains a significant proportion of total TFP variance in nearly all countries of our analysis, we further investigate trend innovations.

Table 7 shows the number of positive trend shocks. Over the whole time period, Italy recorded the lowest number of positive trend shock (31), while the USA the largest (48). In most recent sub-period (2001-2017), data confirm the analysis of Table 1 according to which UK, Germany, Japan and USA experienced the most dynamic TFP growth rates. Again, Italy is the country with the lowest number of positive trend shocks (8).

\subsection{Deep Determinants of Economic Growth}

To provide some explanations for the differences observed in TFP secular trends among the seven advanced economies, we turned ourselves to analyze the 'deep' determinants of economic growth such as the presence of efficient markets and institutions, efficient mechanisms of creation and transmission of knowledge, the degree of international integration. We also limited our analysis to the most recent sub-period for which more data on the 'deep' determinants of economic growth are available.

As discussed above, one of the most powerful mechanisms behind TFP dynamics is the ease of each economy to reallocate resource that favors productivity-improving 
activities. The reallocation of resources from less to more productive businesses is mainly affected by businesses' dynamism, both in terms of growth and contraction. A less dynamic business growth distribution is associated with lower productivity growth. Importantly, both a higher share of growing and shrinking firms are correlated with faster productivity growth. This business churning means more experimentation/innovation and, in the long run, higher productivity through the selection of the most efficient firms. In a 'lock-in context', such as the Italian one, firms are following a risk-averse approach. Too many firms appear either unwilling or unable to experiment and exploit new growth opportunities. As a result, they fail to innovate effectively. The benefits of innovation are only maximized when firms build on it. This means expanding and replacing less successful firms, driving productivity, and the GDP growth in the process. ${ }^{18}$

To generate its benefits this process needs an environment where not just barriers to entry, but also barriers to growth and contraction, such as improving product and labour market regulation, better access to finance and to markets across borders, are removed. Table 8 summarizes some data related to the ease of doing business, competitiveness, and innovation in our countries in the recent years. The first two rows of Table 8 show the ranking on the ease of Doing Business (DB) in 2005 and 2017 (World Bank 2006, 2018a). DB ranking captures eleven important dimensions of the regulatory environment affecting domestic firms. It provides quantitative indicators on regulation for starting a business, dealing with construction permits, getting electricity, registering property, getting credit, protecting minority investors, paying taxes, trading across borders, enforcing contracts and resolving insolvency. DB also measures features of labor market regulation which are reported as a separate section and not included in the ranking.

USA is the country with the best ranking (lowest score), followed by UK, in both years. Japan registers a deterioration of the ranking losing 24 positions between 2005 and 2017, while, for instance, France gained 13 positions. Although Italy has improved its ranking, it is still the country with the worst ranking. That is, Italy is the economy with the worst conditions to do business. ${ }^{19}$

If we rank our countries according to the number of innovations of the recent period (better rank higher number), and compute Spearman's rank correlation coefficient between the ease of doing business and the number of innovations, it is equal to 0.77 , and statistically significant al the $5 \%$ probability level. In particular, the positive TFP innovations seem to translate into higher GDP growth in those countries characterized by more efficient deep determinants, largely supporting the hypothesis according to which long-run TFP performance is positively related to the degree of institutional and market efficiency.

\footnotetext{
18 See Bravo Biosca (2010).

19 The Italian economy, especially its manufacturing, still finds itself 'locked-in' with a production structure that on average has not been changing much during the last 25-30 years and failed to converge towards the most developed European countries such as France and Germany. However, it is not clear if this 'lockin effect' is the cause or the result of the 'missing' intertemporal substitution of productivity-improving activities. More likely the two phenomena tend to reinforce one-another and increase the gap between the Italian TFP and that of the other most industrialized countries.
} 
Table 8 Trend innovations and their deep determinants (2001-2017)

\begin{tabular}{llllllll}
\hline & France & Germany & Italy & Japan & Spain & UK & USA \\
\hline DB 2005 $^{\mathrm{a}}$ & 44 & 19 & 70 & 10 & 30 & 9 & 2 \\
DB 2017 $^{\mathrm{a}}$ & 31 & 20 & 46 & 34 & 28 & 7 & 6 \\
Number of innovation $^{\mathrm{b}}$ & 11 & 13 & 8 & 11 & 10 & 14 & 13 \\
GDP growth rate $^{\mathrm{c}}$ & 1.11 & 1.57 & -0.06 & 0.76 & 1.12 & 1.52 & 1.76 \\
\hline
\end{tabular}

${ }^{\mathrm{a}} \mathrm{A}$ high ranking on the ease of doing business index means that the regulatory environment is more conducive to the starting and operation of a local firm (World Bank 2006, 2018b).

${ }^{\mathrm{b}}$ From Table 7 as number of innovations for the period 2001-2017.

${ }^{c}$ Annual percentage growth rate of GDP at market prices based on constant local currency (2005-2017). Aggregates are based on constant 2010 U.S. dollars (World Bank)

\section{Alternative Trend and Cycle Decomposition}

As stated above, the analysis of the time series and the definition of cycle and stochastic trend used in this paper follow the literature on the breakdown of series in the short and long run. Thus, the diversity and contribution of our analysis lies in the fact that the breakdown is obtained through a statistical methodology based on the concept of cointegration, which does not require any theoretical a priori.

We can however ask ourselves what relationship exists between this methodology, that enhances the stochastic properties of the time series, and the more traditional ones, such as the Hodrick-Prescott filter (HP) $(1981,1997)$, where it is assumed that the trend is deterministic although not linear. Thus, in this section we present results obtained by means of HP filter.

Like other trend removal techniques such as trend regression, moving average detrending, and band-pass filtering, the HP filter is often used to produce new time series such as potential GDP and the output gap that are useful in macroeconomic modeling and monetary policy research. Recently, the usage of the HP filter as a measure of potential output is debated (Phillips and Jin 2015; Hamilton 2018). On the one side, the HP filter can encompass long run behavior related to a vast range of alternative data generated processes. On the other side, a drawback discussed by Phillips and Jin (2015) is related to the finding that the processes that lie within the natural capture range of the HP filter depend on the value of the smoothing parameter in relation to the sample size. Accordingly, Hamilton (2018) argues that the HP filter produces series with spurious dynamic relations that have no basis in the underlying data-generating process; moreover, filtered values at the end of the sample are very different from those in the middle, and are also characterized by spurious dynamics; finally, the smoothing parameter should theoretically have values largely different from common practice values. ${ }^{20}$

However, keeping in mind these limitations, additional evidence can help to improve our knowledge of trends and cycles and their relationship and correlation over time.

\footnotetext{
20 Hamilton (2018) proposes an OLS regression of the observed non-stationary time series on a constant and its four most recent values. The stationary, or cyclical, component is then obtained from the residuals. Schuler (2018) argues that Hamilton's ad hoc formulation of a 2-year regression filter implies a cancellation of 2-year cycles and an amplification of cycles longer than typical business cycles.
} 
Table 9 Correlations between innovations and variance decomposition analysis 1955-2017 (HP trend series)

\begin{tabular}{llll}
\hline & Correlation coefficients & Trend innovations $^{a}$ & Cycle innovations $^{b}$ \\
\hline Germany & $-0.27^{* *}$ & 39.5 & 60.5 \\
France & $-0.36^{* * *}$ & 35.7 & 64.3 \\
Italy & $-0.35^{* * *}$ & 22.3 & 77.7 \\
Japan & $-0.33^{* * *}$ & 31.0 & 69.0 \\
Spain & -0.21 & 55.6 & 44.4 \\
UK & $-0.44^{* * *}$ & 23.8 & 76.2 \\
USA & $-0.31^{* *}$ & 37.0 & 63.0 \\
\hline
\end{tabular}

$* * *, * *, *$ Statistically significant at the $1 \%, 5 \%$ and $10 \%$ probability level

a $\%$ of the variance of TFP innovation attributed to trend innovations

$\mathrm{b} \%$ of the variance of TFP innovation attributed to cycle innovations

To this aim, we apply the HP filter to the original TFP series to obtain trend and cycles, and replicate the analyses of the previous Sect. 4, Tables 6 and 7.

Table 9 shows results of the correlation analysis between trend and cycle innovations obtained by means of the HP filter in each country, and their variance decomposition analysis (see Table 6 for comparison). For all countries, trend innovations are computed as follows. As first differences of the HP trend series are always autocorrelated, we first differentiate the percentage variation of the trend series and then define trend innovations as residuals of ARIMA $(2 ; 0 ; 1)$ models of these new series. ${ }^{21}$ Cycle innovations are defined as the residuals of the first differences of AR(1) models for all countries, but Spain and Germany, for which the models are AR(2).

As in the previous analysis, trend and cycle innovations are negatively, and statistically significant, correlated in all countries, except Spain, supporting again the 'opportunity cost' approach to productivity growth for these countries.

As for results related to the variance decomposition of Table 9, we obtain that, differently from the previous section, the contribution of cycle innovations is generally larger than that of trend innovations. Indeed, HP filter generates a smoothed trend, so that part of the variance that in the CTCC decomposition is attributed to the stochastic trend, when using HP filter it is attributed to the cycle, likely explaining the reason for the different innovation weights. Therefore, while the findings of Table 9 are consistent with the hypotheses at the basis of the HP methodology, we still may argue that low frequency movements in aggregate time series continue to explain an important proportion of aggregate variance.

Finally, Table 10 shows the number of positive trend shocks. Differently from results of the previous Table 7 , if we consider the whole period, or just the most recent sub-period (2001-2017), data do not confirm the analysis of Table 1. Indeed, according to Table 10, the most dynamic TFP growth rates are recorded in Spain (36

\footnotetext{
21 The HP trend and cycle decomposition was made by using GRETL program, version 2020b. We also use alternative definitions of trend innovations such as residuals from ARIMA models applied at the log of the original HP trend series. Findings are consistent with those presented in this section and available upon request from the authors.
} 
Table 10 Number of positive trend innovations ${ }^{a}$

\begin{tabular}{lllllll}
\hline & $\leq 1980$ & $1981-1990$ & $1991-2000$ & $2001-2010$ & $2011-2017$ & $1951-2017$ \\
\hline Germany & 10 & 6 & 5 & 6 & 3 & 30 \\
France & 10 & 6 & 6 & 7 & 5 & 34 \\
Italy & 11 & 5 & 5 & 7 & 5 & 33 \\
Japan & 11 & 4 & 7 & 8 & 5 & 35 \\
Spain & 11 & 3 & 5 & 10 & 7 & 36 \\
UK & 15 & 5 & 5 & 3 & 1 & 29 \\
USA & 10 & 8 & 6 & 4 & 4 & 32 \\
\hline
\end{tabular}

${ }^{a}$ Innovations are defined as residuals from ARIMA $(2 ; 0 ; 1)$ models of the differential of the percentage variation of the HP trend series

and 17) and Japan (35 and 13), while the country with the lowest number of positive trend shocks is the UK (29 and 4). These findings might be related to the fact that HP filter suffers from a pro-cyclical bias in end-of-sample trend estimates (Mohr 2006). ${ }^{22}$ Moreover, these findings are also related to Hamilton (2018). Indeed, the HP filter has serious drawbacks that should severely restrict its application. It involves several levels of differencing, so that for random walk series, subsequently observed patterns are likely to be artefacts of having applied the filter, rather than due to the underlying data-generating process.

We have already discussed at length the difficulty of defining an objective decomposition between trend and cycles. A deterministic filter can give great importance to cyclical components, while stochastic trends and co-integrated cycles can transform transitory shocks into permanent effects. We believe that the advantage of the CTCC approach is to provide a statistical methodology that reduces the range of subjectivity on the topic of time series decomposition. Accordingly, we may conclude that stochastic components are essential elements in any analysis of macroeconomic fluctuations and that their correlation can be successful in explaining the long- and short-run properties of the data analyzed in this paper (Nelson and Plosser 1982).

\section{Conclusion}

In this paper we applied the common-trend and common-cycle methodology to identify trend and cycle components of Total Factor Productivity in five major European countries (Germany, France, Italy, Spain and UK) Japan, and the USA. Subsequently, to identifies some of the so-called 'deep' determinants of trend TFP in each economy.

We found that the seven TFP series share a single common cycles, but they share more than one single common stochastic trend. Indeed, the number of common stochastic trend is equal to six that, together with the finding of a single common cycle, gives rise to a special situation according to which we were able to identify trend and cycle components without imposing a priori conditions on the relationships

\footnotetext{
22 As discussed in Mohr (2006) the trend values of the last sample periods can change significantly when the sample is extended with the arrival of new data.
} 
existing among the different type of shocks in the economy, as in the case of other time series decomposition analyses.

Although TFP dynamics in advanced economies has been investigated before, finding six stochastic trends and a common cycles constitutes new evidence regarding this data. Moreover, this finding is relevant for calculating more precisely the relative importance of permanent and transitory shocks at business-cycle horizons, as the persistent and possibly permanent effects of recessions imply that what we refer to as cyclical events might affect the secular trend (Cerra et al. 2020).

Once the trend TFPs of the seven economies were calculated, we tried to speculate on some of their 'deep' determinants, namely efficient markets and institutions.

Our results, using data on the most recent sub-period (2001-2017) for which we were able to collect information, seem to support our hypothesis according to which long-run TFP performance is positively related the degree of institutional and market efficiency. Thus, these findings, though essentially descriptive and not generalizable given the limited number of observations, are consistent with our hypothesis that in those economies equipped with greater growth potential trend positive shocks turn into stronger GDP growth. However, further research is needed along this direction.

As policy implications, we believe that governments should increasingly aim at reducing market imperfections that hinder businesses' dynamism and, consequently, the reallocation of resources from less to more productive investment, and improving the mechanisms of creation and transmission of knowledge, especially those related to universities. Policies aimed at solely reform labor market, raising its flexibility, without driving firms towards innovation and skilled investments can have the unintended consequence to weaken the degree of competition and the aggregate technology advancements of economies.

Funding Open access funding provided by Università degli Studi di Urbino Carlo Bo within the CRUICARE Agreement.

\section{Compliance with Ethical Standards}

Conflict of interest The authors declare that they have no conflict of interest.

Open Access This article is licensed under a Creative Commons Attribution 4.0 International License, which permits use, sharing, adaptation, distribution and reproduction in any medium or format, as long as you give appropriate credit to the original author(s) and the source, provide a link to the Creative Commons licence, and indicate if changes were made. The images or other third party material in this article are included in the article's Creative Commons licence, unless indicated otherwise in a credit line to the material. If material is not included in the article's Creative Commons licence and your intended use is not permitted by statutory regulation or exceeds the permitted use, you will need to obtain permission directly from the copyright holder. To view a copy of this licence, visit http://creativecommons.org/licenses/by/4.0/.

\section{References}

Aguiar-Conraria L, Soares ML (2011) Business cycle synchronization and the Euro: a wavelet analysis. J Macroecon 33:477-489

Antonelli C, Crespi F, Scellato G (2013) Internal and external factors in innovation persistence. Econ Innov New Technol 22(3):256-280 
Bernard AB, Durlauf SN (1995) Convergence in international output. J Appl Econom 10(2):97-108

Blanchard O, Quah D (1989) The dynamic effects of aggregate demand and supply disturbances. Am Econ Rev 79:655-673

Bogliacino F, Pianta M (2013) Profits, R\&D and innovation: a model and a test. Ind Corp Change 22(3):649_ 678

Bravo Biosca A (2010) Growth dynamics. Exploring business growth and contraction in Europe and the U.S., Nesta Research report: November 2010

Burns AF, Mitchell WC (1946) Measuring business cycles. National Bureau of Economic Research, New York

Calcagnini G (1995) Common trends and common cycles in international labor productivity. Econ Lett 48:179-184

Calcagnini G, Travaglini G (2014) A time series analysis of labor productivity. Italy versus the European countries and the U.S. Econ Model 36:622-628

Calcagnini G, Ferrando A, Giombini G (2015) Multiple market imperfections, firm profitability and investment. Eur J Law Econ 40(1):95-120

Calcagnini G, Giombini G, Travaglini G (2018) A Schumpeterian model of investment and innovation with labor market regulation. Econ Innov New Technol 27(7):268-651

Cerra V, Fatas A, Saxena SC (2020) Hysteresis and business cycles. CEPR Discussion Papers, DP14531

Chen X, Mills TC (2009) Evaluating growth cycle synchronisation in the EU. Econ Model 26:342-351

Dedrick J, Gurbaxani V, Kraemer KL (2003) Information technology and economic performance: a critical review of the empirical evidence. ACM Comput Surv 35(1):1-28

Degiannakis S, Duffy D, Filis G (2014) business cycle synchronization in Eu: a time-varying approach. Scott J Polit Econ 61(4):348-370

Dosi G, Roventini A, Russo E (2019) Endogenous growth and global divergence in a multi-country agentbased model. J Econ Dyn Control 101:101-129

Eichengreen B, Park D, Shin K (2017) The global productivity slump: common and country-specific factors. Asian Econ Pap 16(3):1-41

Elliott G, Rothenberg TJ, Stock JH (1996) Efficient tests for an autoregressive unit root. Econometrica 64:813-836

Engle RF, Issler JI (1995) Estimating common sectoral cycles. J Monetary Econ 35(1):83-113

Feenstra RC, Inklaar R, Timmer MP (2013) PWT 8.0 - a user guide. http://www.rug.nl/research/ggdc/data/ pwt/v80/pwt_80_user_guide.pdf

Feenstra RC, Inklaar R, Timmer MP (2015) The next generation of the Penn world table. Am Econ Rev 105(10):3150-3182

Fuentes R, Mishra T, Scavia J, Parhi M (2014) On optimal long-term relationship between TFP, institutions, and income inequality under embodied technical progress. Struct Change Econ Dyn 31:89-100

Furceri D, Karras G (2008) Business-cycle synchronization in the EMU. Appl Econ 40(12):1491-1501

Gehringer A, Martínez-Zarzoso I, Danzinger FN-L (2016) What are the drivers of total factor productivity in the European Union? Econ Innov New Technol 25(4):406-434

Griliches S (1994) Productivity, R\&D, and the data constraint. Am Econ Rev 84(1):1-23

Groth C, Gutierrez-Domenech M, Srinivasan S (2004) Measuring total factor productivity for the United Kingdom. Bank of England Quarterly Bulletin. Spring, Berlin, pp 63-73

Hamilton JD (2018) Why you should never use the Hodrick-Prescott filter. Rev Econ Stat 100(5):831-843

Hansen GD, Ohanian LE (2016) Neoclassical models in macroeconomics, NBER Working Paper 22122

Hodrick RJ, Prescott EC (1997) Postwar business cycles: an empirical investigation. J Money Credit Bank 29:1-16

Hodrick RJ, Prescott EC (1981) Postwar U.S. business cycles: an empirical investigation. Discussion Paper no. 451, Carnegie Mellon University. Published in updated form as Hodrick and Prescott

Inklaar R, Jong-A-Pin R, De Haan J (2008) Trade and business cycle synchronization in OECD countries: a re-examination. Eur Econ Rev 52(4):646-666

Inklaar R, Woltjer P, Albarran DG (2019) The composition of capital and cross-country productivity comparisons. Int Prod Monit 36:34-52

Isaksson A (2007) Determinants of total factor productivity: a literature review.UNIDO Staff Working Paper $02 / 2007$

Issler JV, Vahid F (2001) Common cycles and the importance of transitory shocks to macroeconomic aggregates. J Monet Econ 47(3):449-475

Johansen S (1988) Statistical analysis of cointegrating vectors. J Econ Dyn Control 12:231-254 
Johansen S (1991) Estimation and hypothesis testing of cointegration vectors in Gaussian vector autoregressive models. Econometrica 59:1551-1580

King RG, Plosser CI, Rebelo S (1988) Production, growth and business cycles. II. New directions. J Monet Econ 21:309-341

Kozicki S (1993) Techniques for estimating dynamic comovement with an application to common international output fluctuations. Finance and economics discussion series. Federal Reserve Board, Washington DC, pp 93-32

Lamperti F, Dosi G, Napoletano M, Roventini A, Sapio A (2018) Faraway, so close: coupled climate and economic dynamics in an agent-based integrated assessment model. Ecol Econ 150:315-339

Lipsey RG, Carlaw K (2000) What does total factor productivity measure? international productivity monitor, Nr. 1, Fall (Unabridged version). http://www.csls.ca/ipm/ipm1.asp

Lucas RE (1988) On the mechanics of economic development. J Monet Econ 22(1):3-42

Manyika j, Roxburgh C (2011) The great transformer: the impact of the Internet on economic growth and prosperity. McKinsey Global Institute, October

Mohr Matthias F (2006) The missing cycle in the HP filter and the measurement of cyclically-adjusted budget balances. Available at SSRN 2005022

Nelson Charles R, Plosser Charles R (1982) Trends and random walks in macroeconmic time series: some evidence and implications. J Monet Econ 10(2):139-162

Phillips PCB, Jin S (2015) Business cycles, trend elimination, and the HP filter, COWLES Foundation Discussion Paper No. 2005, June

Romer PM (1986) Increasing returns and long-run growth. J Polit Econ 94(5):1002-1037

Russo E, Foster-McGregor N, Verspagen B (2019) Characterizing growth instability: new evidence on unit roots and structural breaks in long run time series, LEM Working Paper Series, n. 29, August

Saint-Paul G (1993) Productivity growth and the structure of the business cycle. Eur Econ Rev 37:861-890

Saltari E, Travaglini G (2010) The productivity slowdown puzzle. Technological and non-technological shocks in the labor market. Int Econ J 23(4):483-509

Solow RM (1957) Technological change and the aggregate production function. Rev. Econ. Stat 39:312-320

Sondermann D (2012) Productivity in the Euro Area. Any evidence of convergence? ECB Working Paper Series, n. 1431

Summers LH (2014) U.S. economic prospects: secular stagnation, hysteresis, and the zero lower bound. Bus Econ 49(2):66-73

Vahid F, Engle RF (1993) Common trends and common cycles. J Appl Econom 8:341-360

World Bank (2006) Doing business in 2006. The World Bank and the International Finance Corporation, Washington DC, Creating Jobs

World Bank (2018a) World development indicators. http://data.worldbank.org/data-catalog/worlddevelopment-indicators

World Bank (2018b) Doing business 2017. The World Bank and the International Finance Corporation, Washington DC, Reforming to create jobs

World Economic Forum (2014) The global competitiveness report 2014-2015. Full, Data edn. World Economic Forum, Geneva

Publisher's Note Springer Nature remains neutral with regard to jurisdictional claims in published maps and institutional affiliations. 